\title{
Conversa com Fernando Cocchiarale
}

Interlocutores: Alexandre Sá, André Sheik, Glória Ferreira, Tania Queiroz Transcrição: Emmanuele Russel, Rayssa Ruiz

André Sheik: Estamos aqui, Fernando Cocchiarale, Glória Ferreira, Tania Queiroz, Alexandre Sá e eu, André Sheik, em uma conversa sobre a arte produzida nos anos 1990. Vamos começar com uma pergunta mais ou menos simples para o Fernando: o que você estava fazendo em $1990 ?$

Fernando Cocchiarale: Em 1990, eu já estava, há sete anos, desde maio de 1983, na Fundação Nacional de Artes (Funarte), no Instituto Nacional de Artes Plásticas (Inap), em um período complicado, pois no início dos anos 1990, quando Fernando Collor assumiu o governo, houve o desmonte da área de cultura. Ele fechou a Funarte e criou o IBAC, Instituto Brasileiro de Arte e Cultura. Sumiram as verbas, mas o Ministério da Cultura não chegou a acabar. Então, nesse período, no início dos anos 90, ao lado desse pano de fundo de desmonte, certas coisas que necessitam de muito tempo para sua maturação continuavam timidamente em curso desde a década de 1980. Refiro-me à multiplicação de secretarias municipais e estaduais de cultura pelas capitais brasileiras e pelas cidades mais importantes do Brasil.

A observação é relevante já que, durante o pós-guerra, foram criadas as instituições que promoveram a emergência tanto da arte abstrata e concreta quanto das vanguardas experimentais que, a partir de 1948, consolidaram o modernismo de ruptura no país.

No Rio de Janeiro, o Museu de Arte Moderna do Rio (MAM-Rio), até seu incêndio, em 1978, era a grande instituição de arte, cujo passado é hoje mitificado, por sua intensidade incontestável. Havia uma cantina que parecia um boteco, onde hoje está situado o bar, em que era possível comprar cerveja de garrafa, ovos cozidos coloridos, ou quibes fritos. Era um point de várias gerações de artistas. Então todo mundo ainda podia também ser um "todo mundo" de 1960. Havia uma intensidade, mas havia também uma espécie de rede, de solidariedade, e de ideias entre os artistas que frequentavam o MAM nos anos 1970.

Nos anos 80, o MAM foi fechado para obras, mas o cronograma atrasou, e a área expositiva do MAM levou alguns anos para reabrir.

Foi nesse período que prosperou a volta à pintura promovida pela chamada Geração 80. Mas ao final dos 80 , já se podia observar a safra de artistas que marcaria as artes dos anos 90. Para tais jovens artistas, o MAM não era mais sua referência espontânea, posto que haviam 
florescido num ambiente em que as exposições da Funarte respondiam pela dinâmica institucional da produção contemporânea no Rio de Janeiro e, em parte, do próprio país.

As grandes instituições estatais (federais, estaduais e municipais) da cultura substituíram nacionalmente as instituições sem fins lucrativos criadas no pós-guerra, sobretudo em São Paulo (Museu de Arte de São Paulo (MASP), MAM, Bienal) e no Rio de Janeiro (MAM).

Isso mostra que já havia uma transição de teor institucional nos anos 90, que pode ser observada, por exemplo, na multiplicação de instituições governamentais em prol do fomento e da difusão cultural iniciados na década de 80 e que avançam, em crise, para a de 90.

Das secretarias estaduais de cultura, criadas por estímulo da existência da Funarte, surgiram ou se transformaram - salões de arte de caráter nacional por quase todas as regiões brasileiras. O Salão de Pernambuco não era um salão de abrangência nacional, não era aberto aos residentes de fora do Nordeste, era regional, como o Salão de Porto Alegre. Todos os salões mais antigos eram regionais. Mas a partir do Salão Nacional de Artes Plásticas, quase todas essas exposições se tornaram salões nacionais abertos aos artistas de todo o Brasil.

Tais eventos contribuíram para a intensificação dos contatos interpessoais entre os artistas do país, que passaram a viajar para a montagem de trabalhos de cunho mais "instalativo", e que, muitas vezes, precisavam da presença de seus autores na montagem.

Além disso, havia uma sensação de familiaridade, de proximidade, daqueles que haviam começado no início dos anos 70 com o que era feito nos anos 90, mas havia coisas que sinalizavam, felizmente, que não se estava voltando para trás no tempo. O dado novo era a volta da pintura como métier, ocorrida mundialmente na década anterior.

Atualmente, ocorre, por, exemplo, uma releitura das possibilidades poéticas da videoarte daquela época: as obras de Letícia Parente, Sonia Andrade e Anna Bella Geiger, por exemplo, foram produzidas num contexto histórico marcado pela ditadura civil-militar.

Hoje, seus trabalhos estão sendo relidos sob o prisma micropolítico feminista, ainda que a intenção de tais artistas não fosse a de fazer uma arte essencialmente feminista, porque, na época em que foram realizados, a única adversária era a ditadura que espreitava a todos.

Naquele momento, a luta política não possuía, portanto, o teor micropolítico atualmente manifesto na luta contra a misoginia, contra o racismo, contra a homofobia. A luta contra o regime militar, evidentemente, não era refratária a essas questões, nem implícita nem explicitamente, embora seu foco fosse mais abrangente. Porém, quando hoje em dia vemos alguns dos vídeos dessas mulheres pioneiras, é impossível não remetê-las à questão feminista. De qualquer maneira, as obras dos anos 70 não eram focadas nessas pautas. 
Na década de 80, havia uma oposição forte à proposta conceitual, como se tudo aquilo que não resultasse da proficiência artesanal, que não fosse gestual ou "matérico", fosse necessariamente cerebral. Como se fosse impossível, para um artista conceitual, trabalhar com prazer. Isso é de um autoritarismo atroz, achar que o prazer vem da mão na massa. É claro que a pintura dos anos 80 não pode ser avaliada por esse ponto de vista, mas seus discursos afirmavam isso.

Os anos 90, fizeram uma espécie de fusão dessas referências. Aqui no Brasil, especificamente, ocorreu um outro fenômeno: a consolidação das galerias de arte, tanto em São Paulo, quanto no Rio de Janeiro. Pela primeira vez, os artistas brasileiros já saíam da escola vendendo seus trabalhos, isso não existia anteriormente.

André Sheik: Collor entra em 89, assume e fica até 92. Qual foi a influência direta das ações dele? E quais foram as mudanças na arte a partir dali?

FC: Havia muitas coisas convergindo, apesar dos fantasmas anticulturais da era Collor. Houve retaliação, o que significa dizer que houve situações muito desagradáveis. Por exemplo, eu me lembro do seguinte: eu trabalhava na Funarte, então sediada no prédio do Museu de Belas Artes, quando, certo dia, fomos avisados que, dentro de duas horas, alguém do Ministério da Cultura viria para lacrar todas as gavetas. Nunca soube quem trouxe a notícia, nem se era falsa ou verdadeira. O fato é que os servidores, em pânico, começaram a esvaziar suas gavetas para proteger seu trabalho de um eventual ataque. Até a gente ir para o prédio do Ministério da Educação e Cultura (MEC), ficamos em um limbo. Tudo ficou desmontado, por algum tempo.

Mas, no anos 90, paralelamente ao desmonte do Ministério da Cultura, também ocorre um outro fenômeno, que acho importante sublinhar. Em relação aos anos 90, é preciso falar, necessariamente, da expansão de mecanismos de fomento à produção artística propostos por empresas privadas. Surge um "Estado" privado, o Itaú Cultural, que propõe o projeto Rumos, tanto de artes visuais quanto de outras linguagens artísticas. Fui curador da primeira e da segunda edições do Rumos Visuais. A primeira edição compartilhei com a Daniela Bousso e com a Angélica de Moraes ${ }^{1}$. O Itaú pretendia fazer o mapeamento da produção artística emergente de todo o Brasil no início dos anos 90.

Na segunda edição, eu fui curador-coordenador do projeto e trabalhei com curadores regionais como, por exemplo, Viviane Matesco, Moacir dos Anjos, Cristina Freire, Jailton Moreira, Marcus Hill, entre outros. Além da exposição coletiva dos selecionados, foi reunido um grande arquivo de referência, o que provavelmente tornou o Itaú Cultural uma espécie de substituto privado de uma instituição federal, como tinha sido a Funarte.

Da mesma maneira, outras instituições federais, alternativas à Funarte, passaram a lançar editais abertos à produção emergente. Não com a abrangência da Funarte, que não se restringia

\footnotetext{
${ }^{1}$ Segundo o site $<$ http://old-portalic.icnetworks.org/rumo/artes-visuais-2/ $>$, os três foram da comissão de seleção de artes visuais nas edições de 1999-2000.
} 
ao fomento e à difusão, pois era muito mais ampla, posto que formulava políticas. Veja o Centro Cultural Banco do Brasil, depois o Paço Imperial, os Correios, a Caixa Econômica Federal, todas instituições federais. Começou-se a criar um circuito a partir dos anos 80, intensificado nos anos 90. É incrível, porque os circuitos vão correspondendo às frações do capital que estão no poder. Agora, por exemplo, quando se vê hoje a Fundação Roberto Marinho com o "museu" deles, a Casa Roberto Marinho, ou o "museu" da Federação das Indústrias do Estado do Rio de Janeiro (Firjan), a Casa Firjan, na antiga mansão dos Guinle, na rua São Clemente (no bairro de Botafogo), quando, enfim, proliferam-se outros lugares assim, percebe-se que é uma terceira onda institucional. É um tipo de instituição que tem menos preocupação com formação, com atração de jovem na idade efervescente, borbulhante, mas tem o objetivo de mostrar. Há coisas como o Instituto Moreira Salles, com exposições excelentes. Não estou falando mal dessas instituições, já que seus perfis têm que ser regularmente atualizados. Nos anos 90, havia uma diferença. Eu não saberia dar nome àquilo, elaborar aquilo. Não havia qualquer coisa de conceitual, aquilo era uma outra coisa, a despeito do fato de se valer do uso da palavra. Então, tinha uma coisa que evocava o momento anterior à volta da pintura dos anos 70, sem que ele estivesse mais lá, era uma coisa que eu não sabia muito bem o que era. Mas conheci muito gente, e muita gente importante veio com o tempo, como o Marcos Chaves e outros artistas excelentes da geração dele, por exemplo, o Zerbini (Luiz Zerbini), ainda que ele tenha surgido na geração anterior, dos anos 80. Mas eu não vejo nada também parecido com o que se desenvolve hoje, não tinha propriamente coletivos, eram grupos, que não duraram muito tempo.

André Sheik: Como a "Dupla Especializada", de Ricardo Basbaum e Alexandre Dacosta?

FC: Mais como o Visorama ${ }^{2}$. Vocês precisam puxar pela minha memória.

Glória Ferreira: Li recentemente um pequeno texto que fala que os critérios de definição da arte - seja da avaliação da arte - têm mudado muito. Os critérios estéticos, o que é belo e o que não é, os critérios de gosto, e os critérios que são mais questões ontológicas. Ou cognitivas.

FC: Ontológicas em relação aos artistas que eu citei?

GF: Não, na arte contemporânea em geral. O que você considera, hoje, como arte contemporânea?

FC: Ah, eu acho que arte contemporânea é tudo aquilo que uma comunidade aceita como arte. Não cabe a mim dizer o que é ou o que não é arte, entendeu? É isso mesmo, eu não sei lhe dizer o que é e o que não é.

(risos)

\footnotetext{
${ }^{2}$ Veja dossiê Visorama na Concinnitas 36, p.55.
} 
Tania Queiroz: É, faz todo sentido. Você falou em uma comunidade, no que ela se consiste para você?

FC: É difícil dizer. Por exemplo: eu imagino que em uma tribo, em uma taba Ianomâmi, com aquelas pinturas corporais, exista significação simbólica e etc. Digamos que ela tenha 100 pessoas, 120, isso já é uma comunidade para mim, naquele aspecto. Mas, se você estiver em um espaço urbano e pensar que muitos jovens têm esse pensamento, sua patota, sua tribo, tudo isso, já é outra comunidade, a comunidade que vai ver performance, por exemplo: "Hoje vai ter o Opavivará não sei onde". Então isso daí é um circuito, que imanta em algumas situações, e sei lá qual o nome que se pode dar a isso. Estético não tem mais sentido, porque o estético é muito relativo à contemplação, proposta no século XVIII, e é um problema antigo. Mas, enfim, eu acho que é um lugar de troca intensa, de intensidades inclusive, de coisas que não são aquelas que nos movem quando a gente está na fila de um banco, nem atravessando uma rua, e tudo, numa certa medida, nos situa de alguma maneira. Eu penso assim, não sei o que é arte. Tem um livro ali que eu comprei e ainda não comecei a ler, do Frederico Morais, Arte É o que Eu e Você Chamamos Arte (Bazar do Tempo, 2018).

Alexandre Sá: Gostaria de agradecer muitíssimo a vocês por terem topado esta conversa conosco. Assim, eu não sei se você lembra Fernando, mas, muito tempo atrás, a gente participou de uns jantares na casa do Helmut...

FC: Sei, sei, sei.

Alexandre Sá: Eu fiquei naquela...

FC: Sobre a Márcia X., né?

Alexandre Sá: Isso, exatamente. Eu ficava com uma obsessão em relação aos anos 90, eu lhe perguntava, perguntava para o Marcos Chaves.

FC: Mas é porque é tanta coisa que, por exemplo, agora você me lembrou da Márcia X., nos anos 90, ela é essencial, e eu tinha esquecido, vocês têm que dar uma de Sócrates aí e puxar.

Alexandre Sá: Isso. Os anos 90 não podem, obviamente, serem pensados como os anos anteriores, e eu achei bonito como você já começou falando um pouco sobre isso. Não dá para exigir dos anos 90 uma relação como nas décadas anteriores. E você já deu um panorama um pouco da relação sistêmica, relação política, eventualmente alguns coletivos, e, mais recentemente, o Agora/Capacete, mais para o finalzinho, dentro de um sistema político árido, né? Curiosamente, tem a Bienal de 94, a de 98, enfim. É, e para atenuar o que você já disse antes, que não tem o assertivo, mas tem algumas constelações possíveis. 
FC: Claro.

Alexandre Sá: Que é um pouco o que você comentou.

FC: $E$ eu nem acho que uma época tem que ter uma identidade estilística, isso é uma coisa que você bota um sapatinho de cristal na Cinderela e, se não couber, corta o dedão que ele encaixa.

FC: É difícil você imaginar isso, essas grades, elas são complicadas, né?

GF: Havia muito a questão da arte conceitual, da palavra etc. Você não acha que há uma diferença muito grande entre conceitualismo e arte conceitual? E arte conceitual como momento histórico, como período?

FC: Não há dúvida sobre isso. Os artistas norte-americanos Joseph Kosuth e Mel Bochner são conceituais históricos, fundadores, posto que propuseram a arte como ideia (oposta, ao menos como questão, à apreensão sensorial).

No entanto, muitos chamam de conceituais os artistas que fazem obras que não podem ser classificadas com base na proficiência técnica em ofícios tais como pintura, escultura, gravura ou desenho. A arte conceitual não é somente isso, porque ela não se reduz à combinação dos diversos fazeres oficinais subordinadas a temas sócio-micropolíticos trabalhados recorrentemente por artistas em uma produção dada.

Portanto, uma coisa essencial na arte conceitual a distingue de tais incompreensões: a correlação entre a ideia e a mídia que, por meio da palavra (ou de conceitos numéricos, por exemplo), questiona o sentido e a função da própria obra de arte.

Ainda que Kosuth tenha referenciado seu projeto ao pensamento de Wittgenstein, é uma desmaterialização de teor quase platônico, não porque ela não seja materializada de algum modo, no sentido sensorial estrito, mas porque o mundo das ideias é um mundo vazio de sensorialidade, posto que pende do teor essencialista da palavra. Nós estamos aqui encarnados, em um mundo sensível.

Entretanto, acho que a arte conceitual influenciou e criou extensões conceitualistas que não são apenas isso. A Land Art e a Body Art são exemplos de tais extensões. Mas a noção da arte conceitual expandiu-se para o mundo, para muitos lugares. Acho importante essa diferença entre conceitualismo e arte conceitual. A arte conceitual é um conceito histórico e portanto restrito ao tempo em que foi proposto. $\mathrm{O}$ mesmo poderia ser dito sobre o impressionismo ou sobre o concretismo, conceitos aplicáveis ao âmbito histórico em que surgiram.

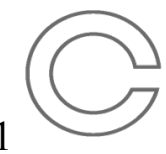


GF: Eu tenho a impressão que a arte conceitual, o conceitualismo, transformou de tal maneira a arte que poderíamos dizer que foi quase como a pirâmide visual no Renascimento.

FC: É verdade, é verdade. Porque virou uma antessala da relação dos artistas, mas sobretudo dos curadores e dos críticos, com a arte passando a ser a antessala da palavra.

GF: É verdade.

FC: Os anos 90 foram muito diferentes. No Brasil, marcaram a consolidação da figura do curador. Isso é uma coisa importante da época. Porque as narrativas formalistas da arte moderna (o abstracionismo, o concretismo e até mesmo o neoconcretismo) eram suficientes para inscrevê-las no circuito sem mediações curatoriais. Quem era neoconcreto sabia que era, e quem não era não se sentia preterido por não ter participado das exposições de tal tendência. Na produção contemporânea, o agrupamento sintático de obras em diferentes ismos da arte moderna foi substituído pela busca semântica que favorecia emergência de temáticas sociopolíticas formalizadas por filtros pessoais - "ah, o meu trabalho discute a sexualidade" , enfim, na vida das artes, na vida cultural, na vida do mercado, na vida em feiras é assim.

Tudo isso tem a ver com a extensão da noção de mercadoria formulada pelo mercado financeiro. Ao contrário da materialidade da fábrica e do produto típica do capitalismo industrial, o mercado financeiro é evanescente, imaterial. Contudo, tal mercado precisa corresponder às expectativas do consumidor privilegiado, que busca, no consumo de marcas e grifes, justificar aquela dinheirama toda. Nesse rol de coisas, está o colecionismo de arte das feiras também. Não é a única forma de arte, não estou dizendo que tudo que seja comercializado seja ruim, nada disso. Apenas que não é a única forma de arte, mas é a forma que se faz hegemônica e corresponde ao mundo em que nós estamos vivendo hoje em dia, um estágio. Todas essas coisas têm que ser aprendidas de uma certa medida.

GF: Outro elemento dos anos 90, que é marcante, é a formação dos novos artistas na universidade ou a sua teorização fora das universidades.

FC: Ah, sim. É verdade, até porque, nos anos 80, no início, se eu não estou enganado, não havia um curso sequer de pós-graduação no Rio de Janeiro.

GF: Isso, nos anos 80, não havia.

FC: O primeiro foi o curso de especialização em História da Arte e Arquitetura do Brasil na Pontifícia Universidade Católica do Rio de Janeiro (PUC-Rio), criado por Carlos Zilio e, se não me equivoco, por Wilson Coutinho, por onde nós passamos. De lá para cá, as coisas andaram nessa área acadêmica. Todos esses dados têm pesos específicos para configurar um panorama, por isso que é muito difícil estabelecer, seja continuidade, seja ruptura, porque as coisas são muito rizomáticas, estão muito entrelaçadas. 
Tania Queiroz: E isso é um assunto a se tocar, porque, ouvindo você falar, acho que dá para perceber a emergência e a ausência de algumas coisas, mas sobretudo a emergência de vários agentes diferentes, não? As galerias, a universidade, a figura do curador, esses salões...

FC: Uma coisa mais próxima do modelo internacional, como se isso fosse automaticamente a solução.

TQ: Mas você acha que isso é movido pelo vislumbre desse modelo internacional, ou é uma coisa interna movida por essas forças?

FC: Acho que essas coisas acontecem meio de cambulhada, nenhuma ideia é passada isoladamente sem penduricalhos.

André Sheik: Você falou do papel do curador, das galerias, das pós-graduações em arte aqui no Brasil. Você acha que a produção dos artistas brasileiros estava muito próxima do que se fazia no exterior? De que maneira ela se diferenciava?

FC: Um pouco de tudo, mas eu acho que a produção brasileira construiu uma experiência histórica da modernidade que começa um discurso, feito por meio de manifestos e por meio de exposições, sobre pesquisas que releem grandes eventos, como a primeira exposição nacional de arte concreta, coisas desse gênero, e até mesmo outras coisas dissidentes disso tudo. Eu acho que esse nível de pesquisa é indispensável, sobretudo quando ela não é movida por um orgulho meio juvenil e ingênuo de inscrição da produção brasileira na arte internacional. Além disso, também não podemos esquecer que a própria arte internacional, sobre a égide de multiculturalismo, não vai querer estimular diferenças que não sejam étnicas e antropológicas.

Também havia uma leitura da arte brasileira que supunha que não se poderia ter arte contemporânea se não houvesse uma experiência moderna, modernista, uma terra bem pavimentada, digerida e elaborada e daí por diante. Isso era um problema, mas tinha mais alguma coisa que eu vou me lembrar.

André Sheik: Falando um pouco de sua carreira de artista, em um momento anterior, tinha ainda o aspecto do artista não poder ser curador.

FC: Tinha! Tinha, até os anos 90. Você vê que o [curador] Paulo Herkenhoff parou de trabalhar, e outros... O [curador] Lauro Cavalcanti, que era artista, é outro exemplo. Era muito difícil para quem vinha de experiências, entre aspas, "sobre a ressonância do conceitualismo", ser, simultaneamente, artista e crítico. Não era considerado ético. Se você tinha uma capacitação específica para legitimar um trabalho, para dizer se ele era bom ou ruim (sendo um crítico, deveria saber mais que a média dos frequentadores do mundo da arte), dispondo dessas ferramentas que os artistas não possuem, você não poderia "concorrer" com aqueles que só

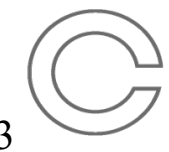


eram artistas. $\mathrm{O}$ artista entraria nesse confronto em condição de desigualdade. Portanto, não era considerado ético ser crítico e curador ao mesmo tempo.

TQ: E como é que você passou de um lugar para outro?

FC: Nos anos 80, as coisas mudaram. Depois de cursar economia, abandoná-la, e estudar no curso de Artes visuais no MAM, em 1972, fui estudar na casa da Anna Bella. Depois disso, eu fiz vestibular de novo, para Design, na PUC. Pensei que era um curso de artes, não era, era Design. Então eu já ia largar de novo e resolvi fazer Filosofia. Com a Anna Bella, eu li o texto "A Arte depois da Filosofia", de Kosuth, e fui estudar filosofia. Então eu me encontrei.

Ainda no início dos anos 80, a pintura retomou o seu antigo poder e se tornou a mídia da década. Eu não queria saber da propalada volta mundial à pintura. Tinha uma boa aptidão artesanal, mas não tinha aptidão pictórica. Dois anos antes, a Geiger havia pedido que eu escrevesse a apresentação de seu livro do Projeto Arte Brasileira Contemporânea (Espaço $\mathrm{ABC}$ ), da Fundação Nacional de Arte. O Ivens Machado gostou de meu texto e solicitou que eu escrevesse para ele. Em seguida, a Essila Paraíso também me pediu que eu escrevesse sobre sua exposição, A História da Arte, no parque da Catacumba, na Lagoa. Aí eu me dei conta: já mudei de lado.

TQ: Entendi.

Alexandre Sá: Foi acontecendo.

FC: Foi isso.

TQ: Alguém tem mais perguntas?

Alexandre Sá: Bom, creio que podemos encerrar, estamos satisfeitos com a entrevista. 